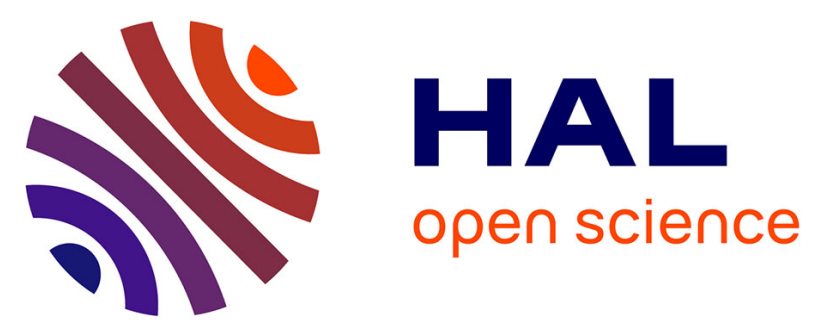

\title{
The baby and the bathwater: On the need for substantive-methodological synergy in organizational research
}

\author{
Joeri Hofmans, Alexandre J S Morin, Heiko Breitsohl, Eva Ceulemans,
} Léandre Alexis Chénard-Poirier, Charles Driver, Claude Fernet, Marylène Gagné, Nicolas Gillet, Vicente González-Romá, et al.

\section{To cite this version:}

Joeri Hofmans, Alexandre J S Morin, Heiko Breitsohl, Eva Ceulemans, Léandre Alexis ChénardPoirier, et al.. The baby and the bathwater: On the need for substantive-methodological synergy in organizational research. Industrial and Organizational Psychology, 2021, 14, pp.497-504. 10.1017/iop.2021.111 . hal-03480562

\section{HAL Id: hal-03480562 https://hal.science/hal-03480562}

Submitted on 14 Dec 2021

HAL is a multi-disciplinary open access archive for the deposit and dissemination of scientific research documents, whether they are published or not. The documents may come from teaching and research institutions in France or abroad, or from public or private research centers.
L'archive ouverte pluridisciplinaire HAL, est destinée au dépôt et à la diffusion de documents scientifiques de niveau recherche, publiés ou non, émanant des établissements d'enseignement et de recherche français ou étrangers, des laboratoires publics ou privés. 


\title{
The Baby and the Bathwater: On the Need for Substantive Methodological Synergy in Organizational Research
}

\author{
Joeri Hofmans* \\ Department of Psychology, Work and Organizational Psychology, Vrije Universiteit Brussel, Belgium \\ Alexandre J.S. Morin* \\ Substantive-Methodological Synergy Research Laboratory, Concordia University, Canada
}

* The first and second author contributed equally to this article and their order was determined at random. Both should thus be considered first authors.

Breitsohl, H., Ceulemans, E., Chénard-Poirier, L. A., Driver, C. C., Fernet, C., Gagné, M., Gillet, N., González-Romá, V., Grimm, K. J., Hamaker, E. L., Hau, K.-T., Houle, S. A., Howard, J. L., Kline, R. B., Kuijpers, E., Leysen, T., Litalien, D., Mäkikangas, A., Marsh, H. W., McLarnon, M. J. W., Meyer, J. P., Navarro, J., Olivier, E., O’Neill, T. A., Pekrun, R., Salmela-Aro, K., Solinger, O. N., Sonnentag, S., Tay, L., Tóth-Király, I., Vallerand, R. J., Vandenberghe, C., Van Rossenberg, Y. G. T., Vantilborgh, T., Vergauwe, J., Vullinghs, J. T., Wang, M., Wen, Z., \& Wille, B.

Acknowledgements: The second author was supported by a grant from the Social Science and Humanities Research Council of Canada (435-2018-0368).

\author{
Corresponding author: \\ Joeri Hofmans \\ Vrije Universiteit Brussel \\ Pleinlaan 2 \\ 1050 Brussel \\ joeri.hofmans@vub.be
}

This is the prepublication version of the following manuscript:

Hofmans, J., Morin, A. J. S., Breitsohl, H., Ceulemans, E., Chénard-Poirier, L. A., Driver, C. C., Fernet, C., Gagné, M., Gillet, N., González-Romá, V., Grimm, K. J., Hamaker, E. L., Hau, K.-T., Houle, S. A., Howard, J. L., Kline, R. B., Kuijpers, E., Leyens, T., Litalien, D., Mäkikangas, A., Marsh, H. W., McLarnon, M. J. W., Meyer, J. P., Navarro, J., Olivier, E., O’Neill, T. A., Pekrun, R., Salmela-Aro, K., Solinger, O. N., Sonnentag, S., Tay, L., Tóth-Király, I., Vallerand, R. J., Vandenberghe, C., Van Rossenberg, Y. G. T., Vantilborgh, T., Vergauwe, J., Vullinghs, J. T., Wang, M., Wen, Z., \& Wille, B. (2021). The baby and the bathwater: On the need for substantivemethodological synergy in organizational research. Industrial and Organizational Psychology. Early view. https://doi.org/10.1007/s12144-021-01807-3

(C) 2021. This paper is not the copy of record and may not exactly replicate the authoritative document published in Industrial and Organizational Psychology. 
In his focal article, Murphy (In Press) argues that the field of Industrial Organizational (I/O) Psychology needs to pay more attention to descriptive statistics when reporting and interpreting research findings. Although we sympathize with the idea that it is important for authors to be clear and open about how their raw data look like, we strongly disagree with the associated claim that "the increasing complexity and diversity of data-analytic methods in organizational research has created several problems in our field" (p. 2). In what follows, we will explain that this claim suffers from two important oversights: (1) it neglects the crucial role of methodological fit, or the notion that theory, methods, and analyses need to be aligned, and (2) it neglects the fact that in I/O Psychology, most of our constructs are not directly observable but need to be inferred indirectly, which necessitates the use of latent variable models. In what follows, we expand on both issues, using several examples to illustrate the point that the increasing complexity and diversity of data-analytic methods in organizational research is not a threat but a blessing for the field of IO psychology (and beyond). We conclude by highlighting the need for substantive-methodological synergies as a solution to some of the issues raised by Murphy (In Press).

\section{The Importance of Methodological Fit}

Methodological fit refers to the "internal consistency among elements of a research project (Edmondson \& McManus, 2007; p. 1155). More specifically, it concerns the alignment between one's research question, prior work on the topic, one's research design (including the type of data being collected and the analyses) and one's contribution to the literature. The direct implication of the idea of methodological fit is that one's data-analytic methods need to be attuned to the theoretical questions one tries to answer, an idea that is also reflected in the well-known statement that "extraordinary claims require extraordinary evidence". Human behavior is multifaceted, complex, and occurs in interaction with equally complex social systems. As a result, if we want to understand human behavior, we need designs and data-analytic methods that allow us to capture this level of complexity. In what follows, we illustrate that in I/O Psychology such complexity can take several forms, thereby necessitating specific requirements on the part of our data-analytic methods, all of which go beyond the simple consideration of descriptive statistics. 
Many phenomena in IO psychology are multidetermined. Although several examples can be given here, one that gained a lot of attention in recent years is the importance of balanced need satisfaction for wellbeing. The core idea of need (im)balance is that individuals with balanced levels of satisfaction in the needs for autonomy, competence, and relatedness are believed to experience higher levels of wellbeing than people with the same level of, yet less balanced, need satisfaction (Sheldon \& Niemiec, 2006). Importantly, the role of need (im)balance cannot be tested using descriptive statistics and correlations because it necessitates a multivariate rather than a univariate approach (Gillet et al., 2019, 2020). Because many of the phenomena in which I/O psychologists are interested are multidetermined, the idea of methodological fit implies that to address these issues complex, multivariate data-analytic methods are required.

Much of our data have a nested data structure. Because people typically work in teams, and teams work in organizations, data in IO psychology often have a nested data structure. The same is true when repeated measurements are taken from the same individuals, in which case measurements are nested within the individuals. The issue is that such data structures create dependencies in the data (e.g., the level of commitment of employees working within the same organization is likely to be more similar than the level of commitment of employees working in different organizations). To properly analyze such data, these dependencies need to be taken into account, which necessitates complex multi-level methods (Morin et al., In Press; Schreurs, Hofmans, \& Wille, 2021). Two examples show how crucial methodological fit is in the case of multilevel data. The first one is the Big-Fish-LittlePond effect from the field of educational psychology (Marsh et al., 2014), where the effect of classroom levels of achievement on academic self-conceptions has been shown to be different (negative) than the effect of individual levels of achievement (positive) due to the action of social comparison mechanisms. The second example pertains to repeated measurements data. McCormick, Reeves, Downes, Li, and Ilies's (2020) meta-analysis shows that, when comparing between-person and within-person associations, associations are different across levels of analysis in $24.1 \%$ of the cases. Likewise, many psychological phenomena (e.g., self-esteem) are known to present trait and state components responding to distinct mechanisms of influences (Perinelli \& Alessandri, 2020). 
Hence, when dealing with nested data, one needs to take potential dependencies in the data into account, and this necessitates multi-level or time-structured models.

The questionable assumption of population homogeneity. Whereas most studies in I/O Psychology implicitly assume that a single set of "averaged" parameters estimated from a sample can be used to describe the population, awareness is growing that this assumption might be too simplistic (Meyer \& Morin, 2016). Hofmans, Wille and Schreurs (2020) argue that several of our theories imply the existence of population heterogeneity rather than homogeneity. For example, vocational researchers increasingly recognize that contemporary careers and career orientations cannot simply be categorized as either boundaryless or protean, and that people rather differ in the extent to which they hold unique combinations of different career orientations. Important for this issue is that, to detect potential population heterogeneity, complex person-centered data-analytic techniques are needed (Morin et al., 2018). Using such techniques, Solinger, van Olffen, Roe, and Hofmans (2013) revealed that the bond between newcomers and their organizations can develop in very different ways, whereas Morin et al. $(2013,2017)$ demonstrated the indissociable nature of self-concept levels and stability. Hence, if we want to relax the questionable and often unrealistic assumption of population homogeneity, we need to embrace complex data-analytic methods.

Some theoretical models, even if simple in appearance, cannot be empirically tested without complex data-analytic methods. The main point here is that some of our theoretical models, in their attempt to capture the complex nature of human reality, have a level of complexity that requires the use of complex data-analytic methods. For instance, Lawler's (1992) seminal theory of empowerment — which argues that one need to jointly consider the complementariness and coherence of leadership empowerment practices to understand their relations with employees' levels of behavioral empowerment — has been around for a long time and is often used in textbooks and as a guide to intervention. However, a proper test of this theory has been lacking, until Chénard-Poirier et al. (2017) were finally able to provide partial support to this theory using a hybrid mixture regression approach. Similarly, Hofmans (2017) argued that to properly test the dynamic model of the psychological contract (Schalk \& Roe, 2007), dual regime models were required. Indeed, dual regime models "closely mimic the theoretical processes underlying the elicitation of violation feelings via two 
model components: a binary distribution that models whether an event in one's work environment leads to a crossing of the acceptance limits of the psychological contract, and a count distribution that models how severe the negative impact of this crossing is." (p. 8). Once again, the core idea of methodological fit that our theories and statistical models should match implies that the complexity of our theories needs to be matched by the complexity of our data-analytical models. Hence, for most of our research questions, looking at descriptive statistics and correlations is not very informative.

\section{The Need for Latent Variable Models}

In I/O Psychology, most of the constructs in which we are interested are not directly observable. We typically rely on questionnaire data, where observed responses to multiple items are assumed to reflect an underlying psychological construct. These unobservable psychological constructs do not come with readily established measurement units (like age, sex, tenure, performance, etc.), but are measured using units of measurement emerging from our data analytic model and those can be a function either of the response scale used in the items, or of the distribution of scores obtained in the sample (standardization) or population (norms) (e.g., Meyer \& Morin, 2016). As a result, our measures are, by definition, imperfect, which makes the sole reliance on descriptive statistics equally imperfect. More globally, our indirect way of measurement poses several challenges, which fortunately can be resolved using more complex (latent-variable) models. In what follows, we list a couple of those challenges that, as a set, illustrate why complex (latent-variable) models are critical for advancing our understanding of work-related phenomena.

Accounting for measurement error. Due to the imperfect nature of our measures, manifest scores contain random measurement error, and this type of measurement error attenuates our estimates of associations between variables. In most research settings, reliable measurement (i.e., true score variance which is the opposite of random measurement error) is reflected in the covariance among ratings obtained across various indicators of the same construct, so that the unique part of each comes to incorporate random measurement error. However, in non-latent analytic models, these two sources of variance (i.e., random measurement error and true score variance) are conflated. Whereas latent variable models naturally separate them, allowing for tests of associations corrected for random measurement errors, properly accounting for measurement error is far more complex than simply 
relying on latent variable models. For example, Marsh and Hau (1996) demonstrated that test-retest correlations based on manifest variables tend to be positively biased by the failure to take into account longitudinal correlated uniquenesses among matching indicators used repeatedly over time. Marsh, Scalas et al. (2010) similarly demonstrated the need to account for the methodological artefact linked to wording effects (e.g., negative wording, parallel wording) to converge on an accurate representation of the underlying structure of our constructs. With multilevel data, these issues become even more complex as measurement errors due to "inter-item agreement" can occur separately across all levels of analyses, and "inter-rater" agreements between raters of the higher-level reality (e.g., members of a workgroup) are also able to bias measurement (Morin et al., In Press). To make matters worse, Marsh, Seaton et al. (2010) have even demonstrated that rather than simply attenuating associations, these multilevel sources of measurement error, in combination, were also able to create artificial associations between constructs (which they referred to as phantom effects). These examples show the importance of moving beyond descriptive and manifest variables when working with constructs for which we ourselves create the unit of measurement.

Better measurement by disentangling different sources of variance. Recent developments in latent variable models have convincingly shown that measurement issues tend to be a lot more complex than previously thought (Morin et al., 2020). For example, in addition to highlighting the need to disaggregate true score variance from random measurement error, statistical research has highlighted the need to account for distinct forms of true score variance emerging between conceptually-related and hierarchically-ordered constructs (Morin et al., 2020). More precisely, exploratory structural equation modeling (ESEM) has been recommended as a way to account for the presence of conceptually-related constructs via the incorporation of cross-loadings (Asparouhov et al., 2015). Likewise, bifactor modeling has been recommended as a way to account for hierarchicallyordered constructs (Morin et al., 2017). As a result, complex latent-variable techniques have significantly advanced our knowledge on measurement in a way that would have been impossible to achieve using simple descriptive statistics.

Moderation. As Murphy (in press) argues, moderator effects are key to many of our models and theories. Moreover, he rightfully argues that tests of moderation suffer from several issues, 
including low reliability of the interaction term and the associated low power for testing moderation effects. However, rather than taking a step back and reverting to descriptive statistics, we feel that it is at least equally useful to take a step forward and work with latent variable models, as these models make it possible to tackle moderation effects in a way that is untainted by unreliability (Marsh et al., 2013). So once again, why not use the strengths of our complex data-analytic methods, which offer clear solutions to many of the issues we are dealing with in our field.

\section{The Baby and the Bathwater: The Need for Substantive-Methodological Synergy}

Having argued that complex data-analytic models are critical when we want to get proper answers to the complex questions we I/O psychologists tend to ask, we have to admit that we do share Murphy's (In Press) concern about the incorrect application and interpretation of those methods and the growing science-practice gap. The phenomenon that Murphy (In Press) describes has been known for decades (Borsboom, 2006; Marsh \& Hau, 2007) and can be tied to multiple issues, including the lack of proper statistical training in graduate school, to the fact that applied researchers often struggle to keep pace with both the fast-paced methodological innovations and with the equally fast-paced at which their theoretical field of research evolves, and finally to the fact that methodological experts often lose sight of the true needs of applied researchers and present statistical innovation in a formal (equation-based) manner that falls well beyond the understanding of applied researchers. However, rather than resorting to descriptive statistics as a way of capturing reality, we strongly believe in an alternative route: Substantive-methodological synergies.

Substantive-methodological synergies are joint ventures in which new methodologies provide novel insights to unresolved substantive issues (Marsh \& Hau, 2007). Such joint ventures typically happen through collaboration between teams of substantive and methodological experts to make sure that the methods are applied correctly, that the findings are translated in a way that they are meaningful to applied researchers and practitioners, and even that new methods really match the needs of the research area. Thus, rather than taking a step back and leaning on the simplest tools available, we argue that I/O scholars need to acknowledge that human behavior is complex and that, to capture such complexity, advanced data-analytic methods are often needed. Unfortunately, whereas true substantive-methodological synergies (i.e., articles in which both methodological innovations and 
theoretical development are placed at the forefront as dual objectives) are welcome in many other areas of psychology, there remain less welcome in many $\mathrm{I} / \mathrm{O}$ journals, due to the erroneous impression that an article should only tackle one main objective. Moreover, the ability to provide a complete and accurate coverage and interpretation of both theoretical and methodological components typically requires more space than that typically available in $\mathrm{I} / \mathrm{O}$ journals. It is our hope that this article might, in the long run, contribute to reduce these obstacles and pave the way for substantive-methodological synergies in organizational research. Thus, rather than throwing the baby (i.e., proper statistical modeling) out with the soiled bathwater (the challenges posed by the correct application and interpretation of these methods), substantive-methodological synergies will make it possible for I/O Psychologists to solve the true problems raised by Murphy (In Press), but without sacrificing the theoretical richness of our field.

\section{References}

Asparouhov, T., Muthén, B.O., \& Morin, A.J.S. (2015). Bayesian Structural equation modeling with cross-loadings and residual covariances. Journal of Management, 41, 1561-1577.

Borsboom, D. (2006). The attack of the psychometricians. Psychometrika, 71, 425-440.

Chénard-Poirier, L.-A., Morin, A.J.S., \& Boudrias, J.-S. (2017). On the merits of coherent leadership empowerment behaviors: A mixture regression approach. Journal of Vocational Behavior, 103, 66-75.

Edmondson, A. C., \& McManus, S. E. (2007). Methodological fit in management field research. Academy of Management Review, 32, 1155-1179.

Gillet, N., Morin, A.J.S., Choisay, F. \& Fouquereau, E (2019). A person-centered representation of basic need satisfaction balance at work. Journal of Personnel Psychology, 18, 113-128.

Gillet, N., Morin, A.J.S, Huart, I., Colombat, P., \& Fouquereau, E. (2020). The forest and the trees: Investigating the globability and specificity of employees' basic need satisfaction at work. Journal of Personality Assessment, 102, 702-713.

Hofmans J. (2017). Modeling psychological contract violation using dual regime models: An eventbased approach. Frontiers in Psychology, 8, 1948. 
Hofmans, J., Wille, B., \& Schreurs, B. (2020). Person-centered methods in vocational research. Journal of Vocational Behavior, 118, 103398.

Lawler, E.E. (1992). The ultimate advantage: Creating the high involvement organization. San Francisco: Jossey-Bass.

Marsh, H. W., \& Hau, K-T. (1996). Assessing goodness of fit: Is parsimony always desirable? Journal of Experimental Education, 64, 364-390.

Marsh, H.W., \& Hau, K-T. (2007). Applications of latent-variable models in educational psychology: The need for methodological-substantive synergies. Contemporary Educational Psychology, 32, 151-171.

Marsh, H.W., Hau, K.-T., Wen, Z., Nagengast, B., \& Morin, A.J.S. (2013). 17. Moderation. In T.D. Little (Ed.), Oxford Handbook of Quantitative Methods, Vol. 2 (pp. 361-386), New York, NY: Oxford University Press.

Marsh, H.W., Kuyper, H., Morin, A.J.S., Parker, P.D., \& Seaton, M. (2014). Big-fish-little-pond social comparison and local dominance effects: Integrating new statistical models, methodology, design, theory and substantive implications. Learning \& Instruction, 33, 50-66.

Marsh, H.W., Scalas, L.F., \& Nagengast, B. (2010). Longitudinal tests of competing factor structures for the Rosenberg self-esteem scale: Traits, ephemeral artifacts, and stable response styles. Psychological Assessment, 22, 366-381.

Marsh, H. W., Seaton, M., Kuyper, H., Dumas; F., Huguet, P., Regner, I., Buunk, A. P., Monteil, J. M, Blanton, H., Gibbons, F. X. (2010). Phantom behavioral assimilation effects: Systematic biases in social comparison choice studies. Journal of Personality, 78, 671-710.

McCormick, B. W., Reeves, C. J., Downes, P. E., Li, N., \& Ilies, R. (2020). Scientific Contributions of Within-Person Research in Management: Making the Juice Worth the Squeeze. Journal of Management, 46, 321-350.

Meyer, J.P., \& Morin, A.J.S. (2016). A person-centered approach to commitment research: Theory, research, and methodology. Journal of Organizational Behavior, 37, 584-612.

Morin, A.J.S., Blais, A.-R., \& Chénard-Poirier, L.-A. (In Press). Doubly latent multilevel procedures for organizational assessment and prediction. Journal of Business \& Psychology. Early view doi: 10.1007/s10869-021-09736-5. 
Morin, A.J.S., Boudrias, J.-S., Marsh, H.W., McInerney, D.M., Dagenais-Desmarais, V., Madore, I., \& Litalien, D. (2017). Complementary variable- and person-centered approaches to exploring the dimensionality of psychometric constructs: Application to psychological wellbeing at work. Journal of Business and Psychology, 32, 395-419.

Morin, A.J.S., Bujacz, A., \& Gagné, M. (2018). Person-centered methodologies in the organizational sciences. Organizational Research Methods, 21, 803-813 .

Morin, A.J.S., Maïano, C., Marsh, H.W., Nagengast, B., \& Janosz, M. (2013). School life and adolescents' self-esteem trajectories. Child Development, 84, 1967-1988

Morin A. J. S., Maïano, C., Scalas, L.F., Janosz, M., \& Litalien, D. (2017). Adolescents' body image trajectories: A further test of the self-equilibrium hypothesis. Developmental Psychology, 53, $1501-1521$.

Morin, A.J.S., Myers, N.D., \& Lee, S. (2020). Modern factor analytic techniques: Bifactor models, exploratory structural equation modeling (ESEM) and bifactor-ESEM. In G. Tenenbaum \& R.C. Eklund (Eds.), Handbook of Sport Psychology, 4th Ed. (pp. 1044-1073). London, UK: Wiley

Perinelli, E., \& Alessandri, G. (2020). A latent state-trait analysis of global self-esteem: A reconsideration of its state-like component in an organizational setting. International Journal of Selection and Assessment, 28, 465-483.

Schalk, R., \& Roe, R. A. (2007). Towards a dynamic model of the psychological contract. Journal for the Theory of Social Behaviour, 37, 167-182.

Sheldon, K., \& Niemiec, C. (2006). It's not just the amount that counts: Balanced need satisfaction also affects well-being. Journal of Personality and Social Psychology, 91, 331-341.

Schreurs, B., Hofmans, J., \& Wille, B. (2021). Multilevel modeling for careers research. In W. Murphy \& J. Tosti-Kharas (Eds.), Handbook for research methods in careers.

Solinger, O. N., van Olffen, W., Roe, R. A., \& Hofmans, J. (2013). On becoming (Un)committed: A taxonomy and test of newcomer onboarding scenarios. Organization Science, 24, 1640-1661. 